\title{
OVER GROTTEN EN GROTTENVORMING OP CURAÇAO, ARUBA EN BONAIRE
}

\author{
DOOR
}

\section{P. WAGENAAR HUMMELINCK}

Elke kenner van de eilanden weet het: Grotten zijn op Curaçao niets bijzonders! Al bezoekt ook niet iedereen de grot van Hato, onze meestbekende en indrukwekkendste grot, of, nog minder, die van Fontein op Aruba en Spelonk op Bonaire, met hun merkwaardige indianenteekeningen - allen kennen de grotten als een opvallend verschijnsel in het Curaçaosche landschap, en menigeen zal zich dan ook hebben afgevraagd, hoe deze grotten toch wel zijn ontstaan en waarom zij zoozeer aan dit landschap zijn gebonden.

Om met de laatste vraag te beginnen. Kalksteen wordt, in vergelijking met de meeste andere gesteenten, gemakkelijk door (koolzuurhoudend) water aangetast. Elk gat, elke spleet waardoor water stroomt, wordt daardoor steeds wijder en kan, op daarvoor geschikte plaatsen, tot het vormen van holen aanleiding geven. De gesteldheid van koraalkalk is daarbij zeer geschikt om een gemakkelijk indringen van regenwater mogelijk te maken - dus is de aanwezigheid van grotten op de eilanden Curaçao, Aruba en Bonaire, welke voor bijna de helft met koraal en schelpkalken zijn bedekt, geheel te verwachten.

Een antwoord op de vraag naar het ontstaan der grotten is niet zoo gemakkelijk te geven; dat is afhankelijk van de opvatting welke men heeft over de waterhuishouding van een kalksteengebied, en dit is iets, waarover al heel wat verschillende meeningen zijn verdedigd. In de literatuur over de grotten van ons gebied heeft deze strijd echter geen duidelijke sporen nagelaten, om de eenvoudige reden, dat slechts zeer weinigen zich op wetenschappelijke wijze met dit onderwerp hebben beziggehouden.

KARL MARTIN was de eerste, die, bij zijn bezoek aan de eilanden in 1885 , het holenvormende proces ernstig bestudeerde. Hij on- 
derscheidt twee soorten grotten: $1^{\circ}$. die, welke hun aanwezigheid danken aan openingen in het oorspronkelijke rif, welke dan later door stroomend water kunnen zijn verwijd; $2^{\circ}$. die, welke onder invloed van de branding der zee zijn ontstaan. Zijn beschouwingen zijn een groote vooruitgang op alles wat vóór hem over dit onderwerp is geschreven, zijn ook thans nog verreweg het belangrijkste, dat ooit hierover is gepubliceerd.

In tegenstelling tot de bekende grot van Fontein, waarbij de invloed van de zee duidelijk is, houdt $\mathrm{M}$ a $\mathrm{r}$ t i n (1888 II, p. 79) de grot van Hato voor een opening in het oorspronkelijke rif, welke later door de oplossende werking van het regenwater en andere verweeringsprocessen nog zou zijn vergroot. Zoo doen ook Friedmann (1860, p. 243), Krämer (1906, p. 297) en misschien ook W i n k l e r (1926, p. 102). Velen kunnen echter ook hier het denkbeeld van een vorming door de branding der zee niet van zich afzetten (S i m o n s, 1868, p. 24; D u y f j e s 1911 , p. 273) - en toch speelt deze hierbij slechts een zeer ondergeschikte rol.

Waar de golven langen tijd achtereen tegen de rotsen slaan, ontstaat - voornamelijk door het schuren van de door het water medegevoerde vaste bestanddeelen, en verder door het aantasten van het water en de afbrekende werking van enkele organismeneen z.g. brandingsnis, welke de kalkrots ter hoogte van de waterlijn ondermijnt. Is de bouw en de samenstelling van het gesteente onregelmatig, doordat er openingen, spleten, of minder weerstand biedende plekken aanwezig zijn, dan vormen zich op deze plaats holten, welke een aanzienlijke diepte kunnen bereiken. De grootste onder hen, de z.g. brandingsgrotten, zijn over het algemeen breed, hebben een weinig ingewikkeld verloop en bezitten gladde, kale wanden. Wat hun hoogte betreft, zijn zij vooral afhankelijk van het getijdeverschil, dat op onze eilanden slechts enkele decimeters bedraagt.

Brandingsnissen en brandingsholten vinden wij overal, waar het water thans tegen de kalkrots klotst, en waar dit vroeger gebeurde, toen de zee de steile randen vormde van de terrassen, welke thans nog de eilanden omzoomen.

Een indrukwekkende brandingsgrot vinden wij bij Boca Tabla, aan de noordkust van Curaçao, tusschen Savonet en Westpunt. Het is een grot van 20-25 meter breed en 20-30 meter diep, waarin de brekers met een donderend geraas komen binnenrollen. Het plafond bevindt zich niet meer dan drie meter boven het wateroppervlak. 
Vierhonderd meter naar het Zuidoosten, bij Boca Kalkie 1), slaan wij een blik in het verleden en in de toekomst van zulk een brandingsgrot. Het lage kalksteenterras aan de kust is daar ingestort boven de bedding van een tijdelijken waterloop welke hier in zee uitmondt. Deze instorting zal zich hoe langer hoe meer landinwaarts voortzetten, het puin zal worden opgeruimd en er zal een open rooi ontstaan, welke, zooals zooveel andere, vanuit het binnenland komend, de kalksteenafzettingen aan de kust doorbreekt om de zee te kunnen bereiken. De Boca Tabla zelf is eveneens als brandingsgrot ontstaan; zij is nog zeer jong, haar ingang is zelfs nog door groote kalksteenblokken versperd.

Het is duidelijk dat de breede, lage ruimten van de grot van Fontein op Aruba, en van Spelonk op Bonaire, ook door de branding zijn gevormd, zooals voor Fontein reeds door M a r t in (1888, I, p. 132), en misschien Bosch (1836, p. 219), Duyfjes (1911, p. 273) en Win kler (1926, p. 102) werd aangenomen. Oorspronkelijk waren het echter grillig gevormde grotten, welke met de zee niets hadden uit te staan, vóórdat zij bij de vorming van den steilen terrasrand werden ontsloten. Wij zien dit aan het ingewikkelde verloop van de diepere deelen, welke aan den mechanischen invloed van het water grootendeels waren onttrokken. De aanwezigheid van druipsteen pleit niet tegen een ontstaan als brandingsgrot; het kan later zijn afgezet.

De grot van Hato is niet door de zee gevormd, evenals de groote grot op de grens van Savonet en St. Hyronimus, in den Seroe di Cueba ${ }^{2}$ ), en de grot van Quadirikiri, ten Zuidwesten van Fontein op Aruba. $\mathrm{Zij}$ zijn eveneens ontsloten door de vorming van een steilen terraswand, maar hun ingang ligt ver boven het lager gelegen terrasoppervlak, en hun bouw verschilt niet van die van de grotten, welke men elders in het kalksteenlandschapaantreft.

Wij moeten deze grotten niet zien als een zeer bijzonder natuurverschijnsel, maar als het resultaat van een aantal processen welke zich afspelen bij de verweering van elk kalksteengebied.

De twee voornaamste verschijnselen welke het vormen van holen in de hand werken zijn, zooals wij reeds zagen, de gemakkelijke oplosbaarheid van koraalkalk, en het feit, dat dit gesteente

1) D.i. de Boca welke op de topografische kaart 1:20.000 den naam Tabla draagt.

2) Ten Noorden van dat deel van den Seroe Bartool, hetwelk op de topografische kaart 1:20.000 Seroe di Cueba is genoemd. 
sterk met spleten en gangen is doortrokken, zoodat het oppervlaktewater gemakkelijk in de diepte kan doordringen. In kalksteengebieden zal het regenwater dan ook niet in hoofdzaak langs de oppervlakte afstroomen, maar daarentegen snel in de diepte verdwijnen. Alle ruimten, welke bij deze verticale waterbeweging een rol spelen, zullen steeds meer worden verwijd, zoodat tenslotte zelfs bij de hevigste regenbuien geen afvloeien langs het oppervlak meer plaats vindt. De ontwikkeling van een landschap, waarbij wij een dergelijken overgang van bovengrondsche naar ondergrondsche afwatering als leiding gevend verschijnsel aantreffen, heet ,verkarsting", zoo genoemd naar het landschap Karst, in het Noordwesten van den Balkan, waar dit proces, met nog andere ,karstverschijnselen", op klassieke wijze is ontwikkeld.

Met het water worden ook alle medegenomen bodemdeeltjes de diepte in gevoerd. Dit zou de vorming van holten in belangrijke mate kunnen tegenwerken, indien het oplossen niet sneller ging dan het opvullen. Slechts daar, waar het karstoppervlak voortdurend met een groote hoeveelheid vreemd bodemmateriaal wordt overstoven - zooals op de eilanden het geval is ten Westen en Zuidwesten van de centrale gebieden, welke uit een gemakkelijk verweerbaar gesteente bestaan - worden de gangen dikwijls verstopt en zal zich een gebrekkige bovengrondsche afwatering kunnen ontwikkelen.

$\mathrm{Na}$ de kartswaterspiegel te hebben bereikt zal het binnengedrongen regenwater over een minder doorlaatbare aardlaag afstroomen, of het zal zich voegen bij een karstwaterlichaam dat zich in de open ruimten van de kalksteenformatie bevindt, om pas later aan den dag te treden of ondergronds in zee af te vloeien.

In de theorieën over grotvorming speelt dit karstwateroppervlak een zeer verschillende rol. Twee opvattingen staan hier in hoofdzaak tegenover elkaar. Volgens de eene speelt het holenvormende proces zich voornamelijk af bóven de karstwaterspiegel, of is hoogstens tot diens directe nabijheid beperkt; volgens de andere worden de meeste grotten onder dit niveau gevormd.

Terwijl door de oudere onderzoekers aan de gesteenteoplossing de belangrijkste rol werd toegedacht, werd later, veelal in tegenstelling hiermede, aan de mechanische werking van het water groote waarde toegekend. Pas in den laatsten tijd is, in de beschouwingen over holenvorming, aan de oplossende werking van het water wederom een groote plaats ingeruimd. Deze oplossing zou dan vooral plaats hebben bij een waterbeweging, in een systeem van volkomen gevulde ruimten. 


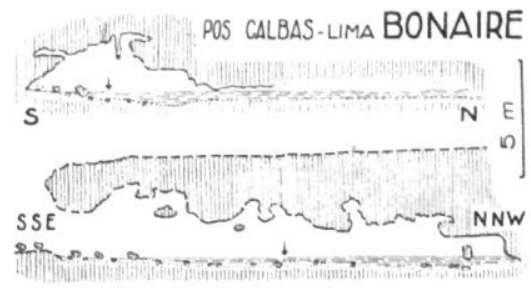

FIG. 1. Lengte- en dwarsdoorsnede (SSE-NNW en S-N) van een kleine grot in het $4 \frac{1}{2}$ meter hooge koraalkalkterras van Zuid-Bonaire. - Een lage ruimte welke zich vrij ver in het gesteente (dat verticaal is gestreept) voortzet en nog voor een deel met grondwater (horizontaal gestreept) is gevuld. Er is veel druipsteen, maar deze is overal inactief. Op het water drijven veel kalkkristallen; de bodem is bedekt met een $z$ wartachtige, naar zwavelwaterst of ruikende modder (gestippeld).

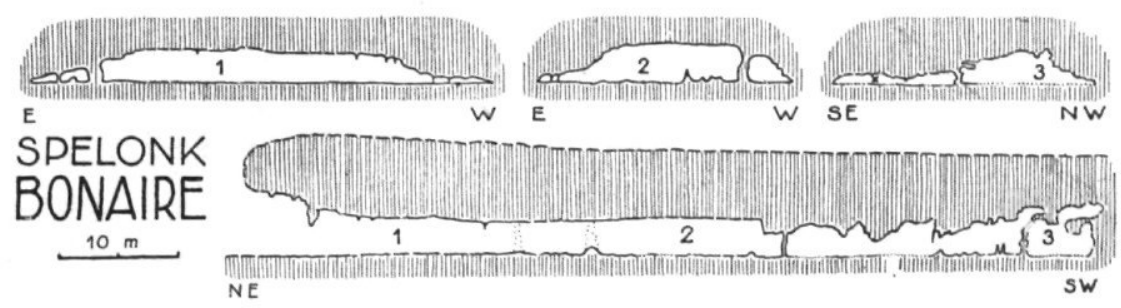

FIG. 2. Lengtedoorsnede en dwarsdoorsneden (NE-SW en E-W, E-W, SE-NW) van een grot in het 12 meter hooge koraalkalkterras van Noordwest-Bonaire. - Vroeger waarschijnlijk een vrij grillig gevormde ruimte, welke later door de zee is verwijd tot een lage, breede hal. Er is veel druipsteen, welke alleen in het verste deel van de grot (een kamer welke op de dwarsdoorsnede SE-NW bij $\times$ is getroffen) nog actief is. De bodem is grootendeels bedekt met een fijne, roodbruine verweeringsgrond.

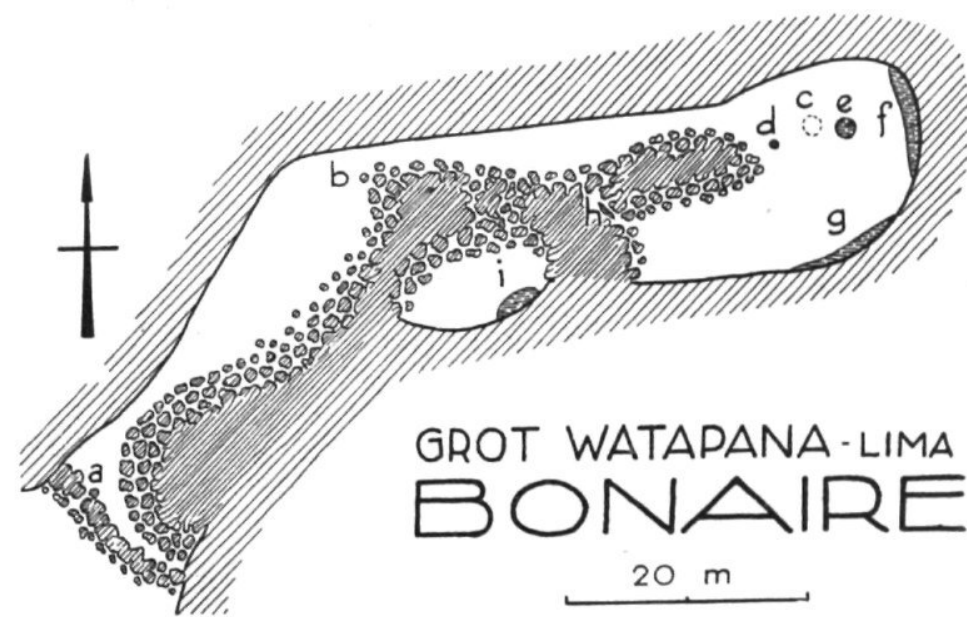
FIG. 3. Schematische plattegrond van een grot in het 6 meter hooge koraalkalkterras van Zuid-Bonaire. - Aanvankelijk een vrij aanzienkle plaatsen in de dieper gelegen gen minder goed toegankelijk is geworden. Op enkele plaatsen in de dieper gelegen deelen komt nog actieve druipsteen voor. De bodem is voor een groot deel bedekt met gevormd, op plaatsen waar het karstwaterlichaam is ontsloten (d, e, f, g, h, i, en c).

West-Indische Gids XXV 


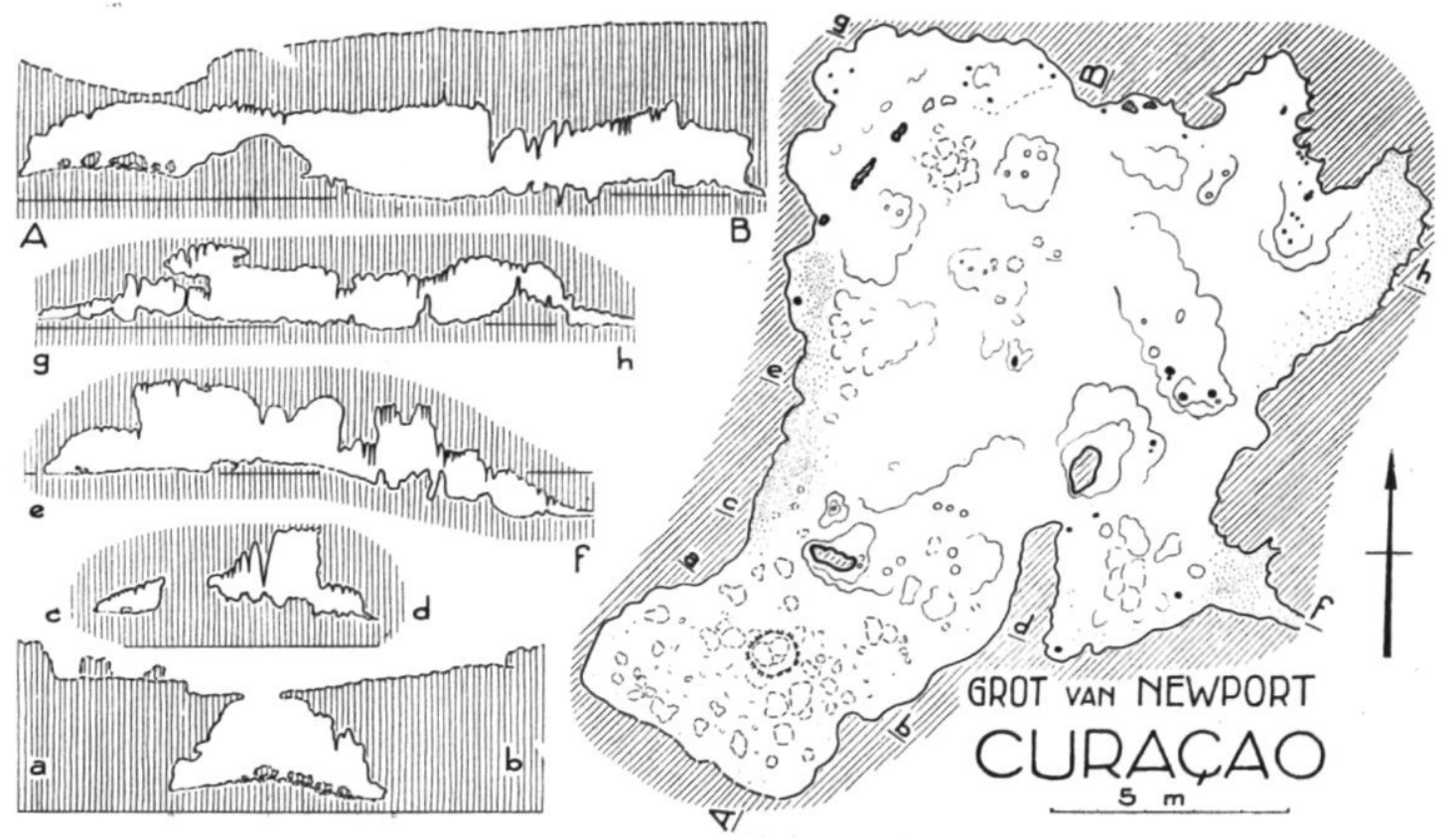

Fig. 4. Plattegrond met lengtedoorsnede en dwarsdoorsneden ( $\mathrm{A}-\mathrm{B}$ en $\mathrm{a}-\mathrm{b}, \mathrm{c}-\mathrm{d}, \mathrm{e}-\mathrm{f}, \mathrm{g}-\mathrm{h}$ ) van een kleine grot in het 8 meter hooge koraalkalkterras van Zuidoost-Curaçao. - Deze grot is in hoofdzaak door de oplossende werking van het grondwater ontstaan. Naderhand hadden er verschillende kleine instortingen plaats, waardoor ook het rond venster (in profiel a-b) werd gevormd. Nadat het water zich had teruggetrokken, werden de wanden en de boden voor het grootste deel met kalksinter (gesloten omtrekken) overtrokken; toen vormden zich de neerhangende stalactieten en de oprijzende stalagmieten (kleine kringen), welke zich soms tot zuilen (zware stippen) vereenigden. Thans wordt geen druipsteen meer afgezet. Waar het oplossingsproces van het regenwater zich het steruipsteet gelden, zooals, behalve aan de oppervlakte, bij den ingang en in het miptee tot de lagstgelegen deelen van de grot beperkt. 


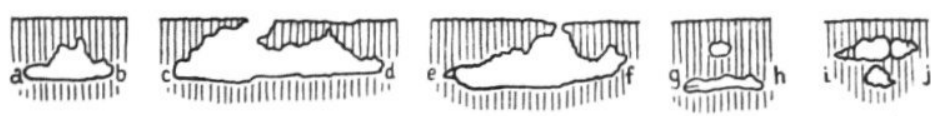

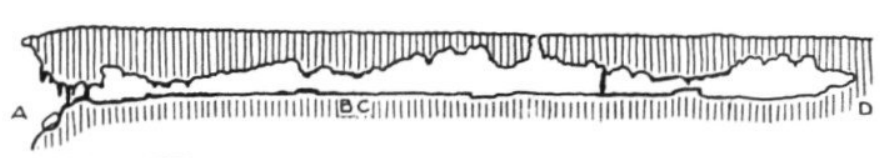

$\sum_{\varepsilon}$

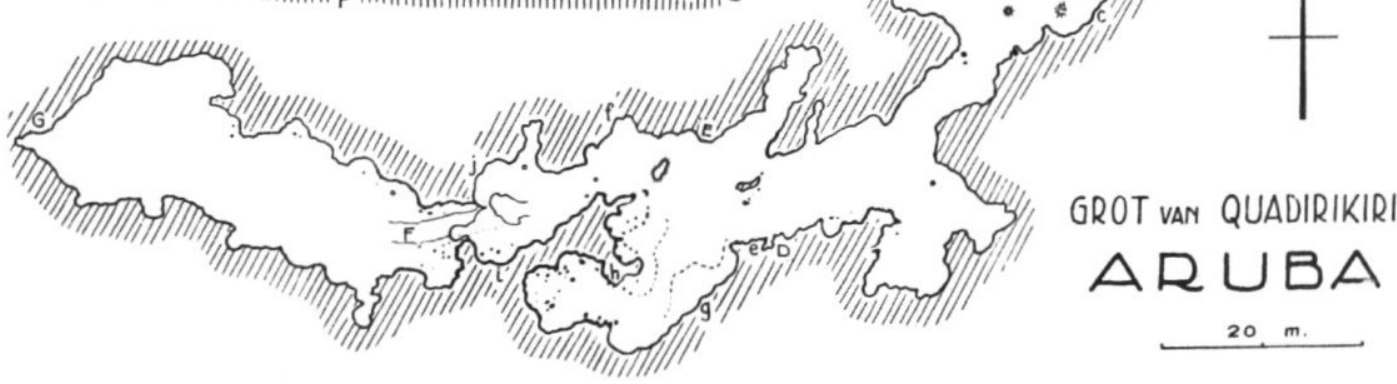

Fig. 5. Plattegrond met lengte- en dwarsdoorsneden (A-BC-D, E-F-G en a-b, c-d, e-f, g-h, i-j) van een grot in het 30 meter hooge koraalkalkterras van Noordoost-Aruba. - Ook deze grot is in atigheden in den bouw van sende werking van het grond. het plater puin nog kon worden opgeruimd. In sommige deelen werd veel druipsteen (dikke of dunne omtrekken tot waar de arceering niet is doorgetrokken) afgezet, terwijl het op andere plaatsen ontbreekt ( dunne omtrekken tot waar de arceering is doorgetrokken). Thans wordt er geen druipsteen meer gevormd. Op veel platsen treden daarentegen oplossingsverschijnselen van het regenwater sterk op den voorgrond, waarsehini de zoldering (profiel $\mathrm{C}-\mathrm{D}, \mathrm{c}-\mathrm{d}, \mathrm{e}-\mathrm{f}$ ) hierdoor eveneens ontstaan. Op plaatse waar een roodbruine verweeringsgrond, welke hier en daar nog door 


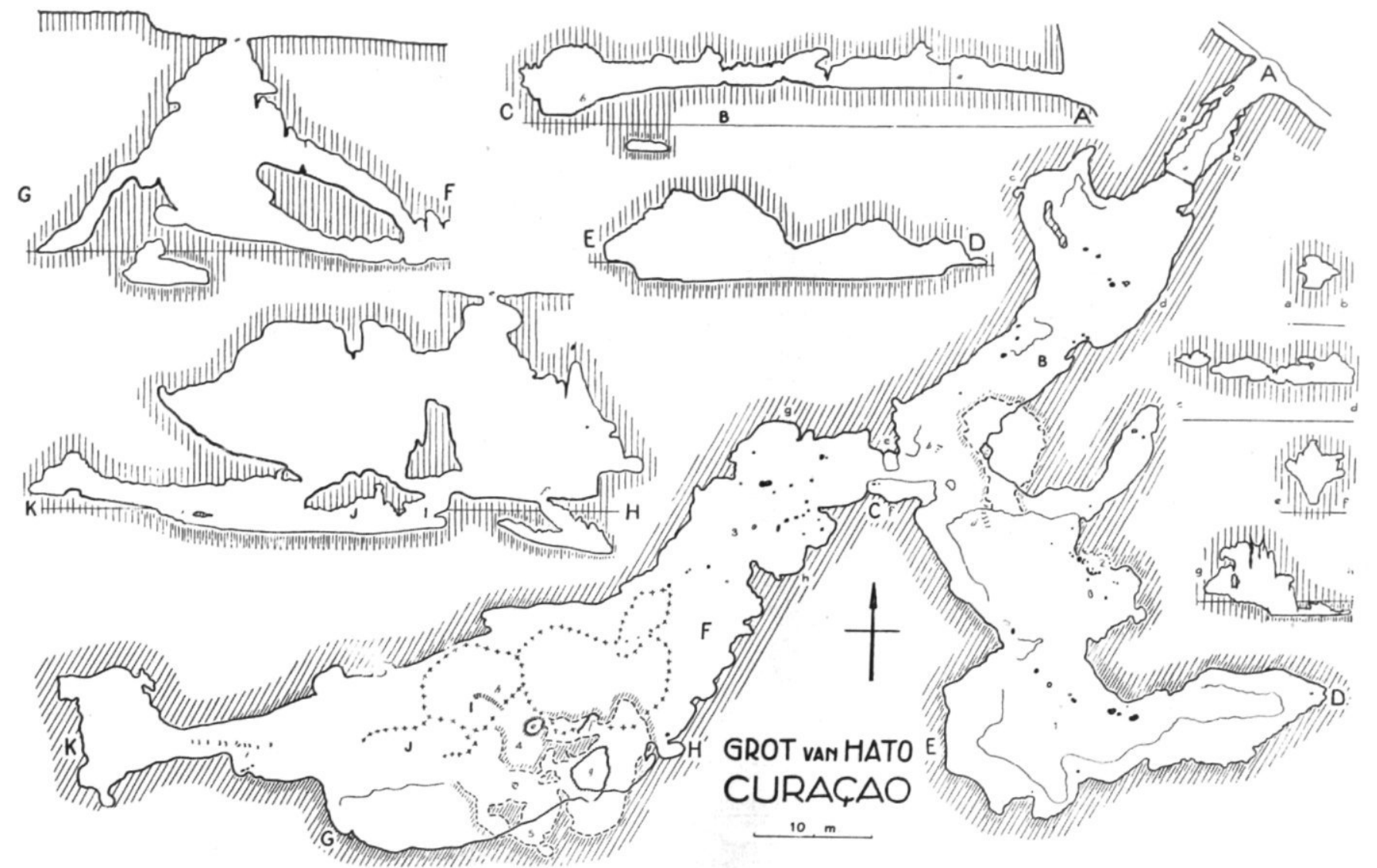

Fig. 6. Plattegrond met lengte- en dwarsdoorsneden (A-B-C, D-E, F-G, H-I-J-K en a-b, c-d, e-f, g-h) van een grot in het 60 meter hooge koraalkalkterras van Midden-Curaçao.- - De vorn vat deze grot, welke eveneens in hoofdzaak door oplossing van het grondwater is ontstaan, fielen $\mathrm{F}-\mathrm{G}, \mathrm{H}-\mathrm{I}-\mathrm{J}-\mathrm{K}$ ) waarin, door een gat in de zoldering (e), het zonlicht binnendringt. (De ontrek van de rrootste a hooge ruimte (proop den plattegrond, met een kruisjeslijn aangegeven). Er is veel druipsteen, maar slechts op enkele plaatsen is deze nog actief; voornamelijk daar, waar zich een waterplas (2) bevindt, welke vrij ver tusschen het gesteente doorloopt. De bodem ligt op verschillende hoor hierbij op de ligging van de hoogtelijn in de profielen; de omtrekken welke hier beneden liggen zijn dubbel gearceerd). Daardoor is het mogelijk dat zich op een lager niveau enkele kleine gangen bevinden, welke door een opening $(c, f, g)$ met de bovenliggende ruimten samenhangen. Op de laagste plaatsen ligt een roodbruine verweeringsgrond, soms door druipsteen of door een dunne kalksteenkorst bedekt. De ingang is door.een deur (a) afgesloten; terwiil men op verschillende plaatsen treden $y, d, h, i$ ) heeft gemaakt, om de grot beter toegankelijk te doen zijn. 
Ook de kalksteengrotten van Curaçao, Aruba en Bonaire zijn in hoofdzaak door oplossing ontstaan, in een tijd, dat zij nog geheel met grondwater waren gevuld. Het grillige verloop der gangen met de blind eindigende zijtakken, het onregelmatige of zelfs terugloopende verval, de sterk wisselende verschillen in breedte en hoogte, de ellipsvormige profielen en de oplossingsvormen in den wand zijn hiervoor aanwijzingen, over wier gezamenlijke beteekenis moeilijk nog kan worden getwijfeld.

Het is niet erg waarschijnlijk, dat, in een latere periode, toen de holen door het dalen van den karstwaterspiegel bijna geheel waren leeggeloopen, ook de afslijpende werking van het water nog belangrijk werk heeft verricht. In dezen tijd werden in de lagere gedeelten een groot deel van de fijne verweeringsproducten afgezet welke den grotbodem nu nog bedekken, en op vele plaatsen vinden wij daarop een dunne korst van kalksteen, zooals heden ten dage nog wordt gevormd door een aaneenkitten van kalkkristallen in enkele ondergrondsche plassen op Zuid-Bonaire ${ }^{1}$ ).

Ongetwijfeld zijn eigenaardigheden in den bouw van het oorspronkelijke rif en van het hieruit voortgekomen kalksteenplateau, van grooten invloed geweest op den vorm van de grotten en op de plaats van haar ontstaan.

Een tweede, zeer belangrijke, vormgevende factor was de gesteentedruk, waarbij door de inwerkende factoren bij voorkeur die deelen van het gesteente werden verwijderd, welke niet aan de drukoverbrenging deelnamen. Voornamelijk door afspringen en instorten ontstonden op deze wijze de hooge, gewelfvormige ruimten, en ook de ronde bovenlichten zijn meestal hieraan te danken.

Bevond zich in de grot, na de instorting, nog stroomend water,

$\left.{ }^{1}\right)$ De oppervlakte van deze plassen is bezaaid met dunne, plaatvormige aggregaten van zeer kleine, zuivere calcietkristalletjes, welke, dank zij gunstige oppervlaktespanningsverschijnselen kunnen blijven drijven, maar door plotselinge bewegingen, of uit zich zelf, als zij te zwaar zijn geworden, zinken.

Wanneer deze plassen buiten hun oevers treden, wat vrij geregeld voorkomt, wordt het overstroomde terrein op den langen duur bedekt met een plaat van brosse kalksteen, welke voor het overgroote deel uit calcietkristallen bestaat. - Fig. 1, Pos Calbas, 1. IV. 1937: Watertemperatuur $26^{\circ} \mathrm{C}$, pH aan oppervlakte $7,7-7,9, \mathrm{Cl}^{\prime}=880 \mathrm{mg} / \mathrm{l}$, $\mathrm{HCO}_{3}{ }^{\prime}=450 \mathrm{mg} / 1$, totale hardheid $\mathrm{D}^{\circ} 32$; luchttemp. $28 \frac{1}{2}^{\circ} \mathrm{C}$, vochtigheid ingang $45 \%$, midden $58 \%$, achter $81 \%$; aggregaten tot $\frac{2}{3} \mathrm{~cm}^{2}$. Fig. 3, Grot Watapana, 1. IV. 1937: Water $30^{\circ} \mathrm{C}, \mathrm{pH} 7,4-7,6, \mathrm{Cl}^{\prime}=$ $1500 \mathrm{mg} / 1, \mathrm{HCO}_{\mathrm{s}}=500 \mathrm{mg} / \mathrm{l}$, tot. hardh. $\mathrm{D}^{\circ} 45$ en $\mathrm{Cl}^{\prime}=1480, \mathrm{HCO}_{3}$ $=260, \mathrm{D}^{\circ} 32$; lucht $30^{\circ} \mathrm{C}$, vocht. $95 \%$; aggreg. tot $3 \mathrm{~cm}^{2}$.

West-Indische Gids XXV 
dan werd het puin hierdoor aangetast en geheel of ten deele weggewerkt; was de grot al drooggeloopen, dan bleef alles liggen. De grootste kans op instorten is dan al voorbij en de wanden worden dan ook niet verder meer in belangrijke mate aangegrepen.

Met het droogvallen is de grot, wat betreft het voornaamste holenvormende proces, inactief geworden; het eerste stadium van haar ontwikkeling is afgesloten. Het tweede stadium is gekenmerkt door het op den voorgrond treden van een in tegengestelde richting werkend proces: het afzetten van kalksinter of druipsteen. Dit wil niet zeggen, dat het begin van de druipsteenvorming het einde beteekent van àlle holenvormende processen. Het oppervlaktewater, dat het gesteente binnendringt, zal doorgaan met het verwijden van spleten en het vormen van holten op daarvoor geschikte plaatsen, en zal op deze wijze ook nog kunnen medehelpen de reeds bestaande grotten te verruimen. In het algemeen echter zal het gesteenteoplossend proces, dat zich boven het karstwaterniveau afspeelt, op de, door het grondwater gevormde grotten slechts in zooverre van noemenswaardigen invloed zijn, als dit het materiaal levert voor de druipsteenafzet tingen, waarmede deze grotten ten deele worden opgevuld.

Nog één stap verder en het stadium is bereikt, waarin ook deze druipsteenafzettingen inactief zijn geworden. In het algemeen is dit het gevolg van een verdere ontwikkeling van de verticale ontwatering van een karstgebied, waarbij het oppervlaktewater snel een lager gelegen niveau bereikt, zonder dat het lang in het bovenliggende gesteente wordt opgehouden, maar ook andere omstandigheden - zooals een verminderde neerslag, ontbossching, het verdwijnen van verweeringsproducten in den bovengrond - kunnen van dit opdrogen van de druipsteenformatie de oorzaak zijn.

In dit stadium van aftakeling, waarin het oplossingsproces aan de lucht hoe langer hoe meer aan beteekenis wint, verkeeren de meeste grotten op de Nederlandsche Benedenwindsche Eilanden. $\mathrm{Er}$ is veel druipsteen, maar slechts op een hoogst enkele plaats komt het nog tot afzetting van nieuwe kalksinter. - Zoo wachten zij op het einde, dat komt, als het kalksteenterras, waarin hun ruimten zich uitstrekken, aan de vernietigende invloeden van de buitenwereld ten offer valt, tenzij zij al reeds eerder, door algeheele instorting, hebben opgehouden te bestaan.

De ontwikkeling van de kalksteengrotten op de Nederlandsche Benedenwindsche Eilanden, zooals deze hier in haar eenvoudigste 
vorm is weergegeven, is in het Curaçaosche landschap stap voor stap te volgen. Grotten in wording vinden wij overal beneden het niveau van het karstwater; grotten in afbraak overal daar, waar de karstwaterspiegel zich tot beneden den grotbodem heeft terug getrokken.

De afbeeldingen werden reeds eerder gepubliceerd in de ,Studies on the Fauna of Curaçao, Aruba, Bonaire and the Venezuelan Islands", vol. 2, 1940; ten deele ook in de "Studies" vol. 1, 1940, in REalino's werk over ,De Nederlandse Antillen" 1938 en in zijn ,,Schoolatlasje” 1940.

De grotten werden opgenomen met kompas en meetlint, in October (Newport), November (Hato), December (Quadirikiri) 1936, Maart (Spelonk) en April (Calbas en Watapana) 1937.

\section{LITERATUUR}

G. B. Bosch, 1836. Reizen in West-Indiê...... II.

M. D. Trenstra, 1836. De Nederlandsche West-Indische Eilanden. I.

S. FriedmanN, 1860. Niederländisch- Ost- und Westindien ....

G. J. Simons, 1868. Beschrijving van het Eiland Curaçou ....

K. Martin, 1888. Bericht über eine Reise nach Niederländisch WestIndien .... I. Land und Leute.

K. Martin, 1888. Bericht .... II. Geologie.

A. KRÄMER, 1906. Curaçao .... Globus 9o, p. 293.

G. DuyfJes, 1911. Het landschap van Aruba. Neerlandia 15, p. 272

O. Winkler, 1926. Niederländisch-Westindien .... Mitt. Ges. Erdk. Leipzig 1923-1925, p. 87.

P. WagenaAr Hummelinck, 1938. De Grotten van Curaçao, Aruba en Bonaire; in: Realino, De Nederlandse Antillen, p. 128.

P. Wagenaar Hummelinck, 1940. Description of the Localities. Studies Fauna Curaçao 2, p. 1.

Over grottenvorming en karsthydrografie in het algemeen raadplege men vooral:

W. M. Davis, 1930. Origin of Limestone Caverns. Bull. Geol. Soc. America 41 , p. 475.

O. Lehmann, 1932. Die Hydrographie des Karstes.

H. CRAMER, 1935. Höhlenbildung und Karsthydrographie. Ztschr, Geomorph. 8, p. 306. 